\title{
Application of the Project Management Body of Knowledge (PMBOK) in an Interdisciplinary Capstone: The AISC Steel Bridge Competition
}

\author{
Aaron Thomas Hill Jr. ${ }^{1, *}$, Madeleine Lyndall Nelson ${ }^{2}$ \\ ${ }^{1}$ Department of Civil \& Mechanical Engineering, West Point, New York, USA \\ ${ }^{2}$ Department of Systems Engineering, West Point, New York, USA \\ Email address: \\ aaron.hill@westpoint.edu (A. T. H. Jr.), madeleine.nelson3@gmail.com (M. L. Nelson) \\ ${ }^{*}$ Corresponding author
}

\section{To cite this article:}

Aaron Thomas Hill Jr., Madeleine Nelson. Application of the Project Management Body of Knowledge (PMBOK) in an Interdisciplinary Capstone: The AISC Steel Bridge Competition. International Journal of Engineering Management. Vol. 3, No. 1, 2019 , pp. 17-24. doi: $10.11648 /$ j.ijem.20190301.14

Received: June 7, 2019; Accepted: July 16, 2019; Published: July 31, 2019

\begin{abstract}
Seven West Point Cadets recently competed in the American Institute of Steel Construction (AISC) Steel Bridge Competition for their capstone project. West Point capstones allow cadets to demonstrate their practical, innovative, and handson solutions to complex problems, serving as an opportunity to demonstrate characteristics required of Army leaders. For purposes of meeting guidelines established by the Accreditation Board for Engineering and Technology (ABET), the capstone serves as a culminating major engineering design experience in at least two civil engineering contexts. It incorporates engineering standards and allows students to apply knowledge and skills from previous coursework. Historically consisting of all civil engineers, this year's interdisciplinary Steel Bridge Team included a systems engineer major for the purposes of improved project management. As tomorrow's leaders are asked to solve complex problems and win in an uncertain tomorrow, the need for graduates to have the skills required to organize chaos, manage risk, establish a schedule and plan, and adapt to change are more important than ever. This paper, organized by the Project Management Body of Knowledge (PMBOK) Process Groups of Initiating, Planning, Executing, Monitoring and Controlling, and Closing, documents the implementation of project management principles towards the West Point Steel Bridge Team's success and their development as future leaders.
\end{abstract}

Keywords: PMBOK, AISC, Steel Bridge Competition, Project Planning, Process Groups

\section{Introduction}

The 2018-2019 West Point Steel Bridge Team, consisting of six civil engineering cadets and one systems engineering cadet, was given nine months to design, fabricate, erect, and test a steel bridge to assist the Hawaii Volcanoes National Park following earthquakes in a fictional scenario. To make matters even more challenging for the team, volcanic flow close to where the bridge was to be erected would cause the team to design a bridge with offset footings, as illustrated in Figure 1. The scenario's open-ended nature required creative thought from the team as each bridge had to have the ability to:

a. Span between 23 and 20 feet on the north and south spans, respectively, b. Support 2,500 pounds (1500 pounds on an undetermined location on the west side of the bridge and 1000 pounds on an undetermined location on the east side of the bridge) without swaying more than one inch or deflecting more than four inches, and

c. Support 50 pounds of lateral load without swaying more than one inch.

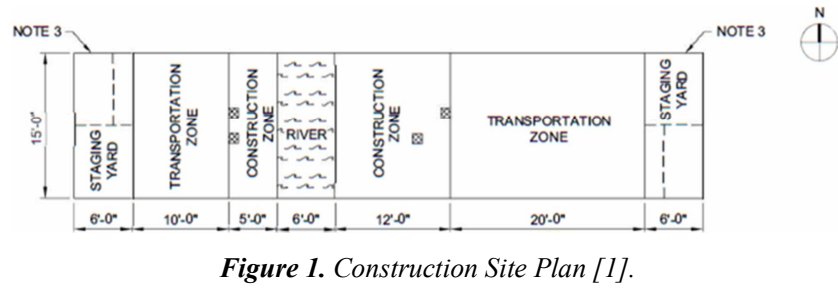


Failure to meet these requirements would result in disqualification from the competition. To add even more complexity, "field conditions" prohibited individual bridge pieces larger than 4 in. x 6 in. $x 42$ in. The Hawaii Volcano National Park Commission, the "client" for the project, expected teams to optimize their design using value analysis based on aesthetics, construction speed, lightness, stiffness, construction economy (function of total time to erect the bridge and total number of builders), and structural efficiency (function of weight, aggregate deflection, and load test penalties). In short, these West Point engineering majors, less than a year from commissioning as $2^{\text {nd }}$ Lieutenants in the US Army, were tasked with applying learned knowledge and skills from their undergraduate coursework using best practice tools and techniques within the Project Management community to successfully plan, design, and build a bridge for the AISC Student Steel Bridge Competition.

\section{Implementing the Initiating Process Group}

\subsection{Creating the Project Charter}

As outlined in the PMBOK Guide $6^{\text {th }}$ ed., the project charter is a partnership between those performing the work and those needing the results of the work. It formally initiates the project and includes the project statement of work, business case, and agreements [2]. Completed at the start of the project management process, a well-conceived project is developed and determined executable within a budget and schedule [3]. For this particular project, West Point cadets have been competing for over 20 years, leaving no doubt as to validity of the project.

Research has shown that the project charter is undoubtedly critical to the success of a project [4]. In the case of this capstone project, the project charter was designed to transform the AISC competition requirements and university program capstone requirements into a documented project management approach. Prior to the development of the project charter, the capstone advisor provided the capstone team with the fundamentals of the Initiating Process Group to improve the project planning process as detailed in the PMBOK Guide (see Figure 2). Fortunately for the team as a whole, one cadet was a member of the previous year's team. In conjunction with the faculty advisor, this experienced cadet provided valuable expert judgment for the team and worked closely with teammates in brainstorming sessions to generate ideas for the project charter. After a few meetings, a consensus was reached, outlining the team's requirements and expected outcomes for each semester.

The team's project charter was not only a formal record of the project. It also served as a formal record of how they would be evaluated with respect to their semester grades. There was a direct link between key requirements to complete the project, student outcome requirements for the engineering programs, and their commitment to excellence. Each semester was broken down into 2000 points with grading designed to capture direct indicators of student outcomes to include:

a. Design. Identify, formulate, and solve complex engineering problems by applying principles of engineering, science, and mathematics.

b. Breadth. Apply engineering design to produce solutions that meet specified needs with consideration of public health, safety, and welfare, as well as global, cultural, social, environmental, and economic factors.

c. Communication. Communicate effectively with a range of audiences (both written and oral).

d. Teamwork. An ability to function effectively on a team whose members together provide leadership, create a collaborative and inclusive environment, establish goals, plan tasks, and meet objectives.

e. New Knowledge. Acquire and apply new knowledge as needed, using appropriate learning strategies.

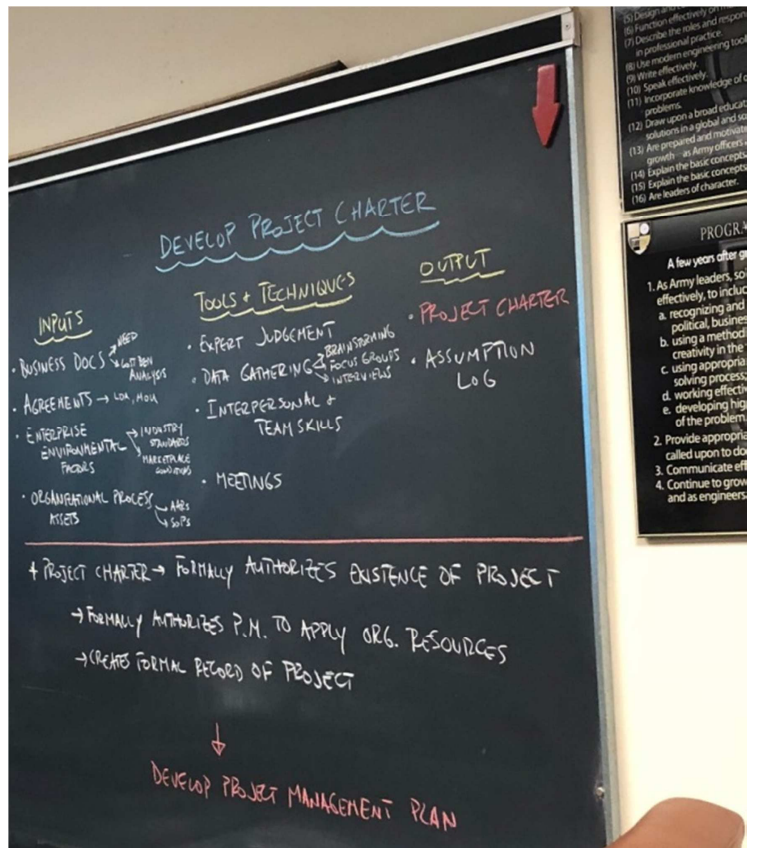

Figure 2. Project Management Lesson from Faculty Advisor.

Table 1 and Table 2 show the critical deliverables in the fall and spring semesters, respectively, detailed within the project charter.

Table 1. Point Allocation in Project Charter, Fall Semester.

\begin{tabular}{lll}
\hline Date & Deliverable & Points \\
\hline 31 August & Contract submitted & 100 \\
6 September & Literature review submitted & 150 \\
17 September & Exam covering competition rules, part 1 & 100 \\
17 September & Project preliminary presentation & 100 \\
21 September & Exam covering competition rules, part 2 & 100 \\
10 October & Presentation of preliminary designs & 150 \\
26 October & Presentation of final designs & 150 \\
14 November & Paperwork submitted to order steel & 100 \\
Various & Project Management lessons & 150 \\
4 December & End of semester presentation & 400 \\
7 December & End of semester paper & 400 \\
11 December & Peer assessment of teamwork & 100 \\
Point total & & 2000 \\
\hline
\end{tabular}


Table 2. Point Allocation in Project Charter, Spring Semester

\begin{tabular}{lll}
\hline Date & Deliverable & Points \\
\hline 16 December & Contract submitted & 100 \\
28 February & Complete bridge fabrication & 100 \\
8 March & Connection testing report & 150 \\
8 March & Load testing and structural analysis report & 150 \\
14 April & Bridge erection rehearsals & 100 \\
16 April & Results of the regional competition & 350 \\
16 April & Oral presentation at the regional competition & 350 \\
2 May & Oral presentation at Projects Day & 350 \\
10 May & End of project written report & 250 \\
10 May & Peer evaluation & 100 \\
Point total & & 2000 \\
\hline
\end{tabular}

\subsection{Identifying Stakeholders}

Typically, project stakeholder analysis consists of stakeholder identification and assessment in order to capture stakeholder requirements, desires, and concerns [5]. Each year, the West Point Steel Bridge Team informally identifies one stakeholder: the AISC regional competition judge. With this being the case, there was never any interaction between the stakeholder and the team until the day of the competition. There were no opportunities for interviews, brainstorming, or focus groups, which is unfortunate given all are techniques identified as project management best practices [2]. Thus, the team was left with reading and understanding the rules and submitting questions on rules unclear to the team to an online system. Understanding the importance of knowing the stakeholder as much as possible, the capstone advisor decided to use the "tool" of holding two exams over the 46page rulebook used by the judge in order to ensure every team member was intimately familiar with their "stakeholder" [1].

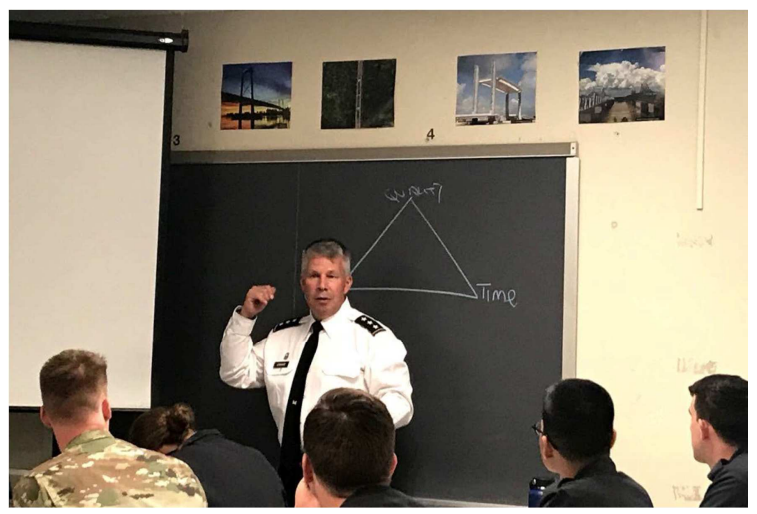

Figure 3. Guest Speaker and Stakeholder, Lt. Gen. Todd Semonite.

This year, with the formal and intentional act of identifying stakeholders, the team was able to brainstorm three other stakeholder groups. First, the team was inspired by a visit and speech from the $54^{\text {th }}$ Chief of Engineers and Commanding General of the U.S. Army Corps of Engineers (USACE) Lt. Gen. Todd Semonite. As shown in Figure 3, he visited cadets in their engineering classes and expressed to these soon-to-be officers in the U.S. Army the need for leaders with values who were energetic, innovative, collaborative, and able to understand the problem. His passionate plea for them to demonstrate the ability solve tough problems and instill a culture of winning drove the team to also identify the faculty, staff, and alumni from both engineering programs as stakeholders. Understanding that their team was representing the preeminent leader development institution in the world and the United States' first institution of engineering education, the team wanted to do more than just complete a good looking bridge for Project's Day. They wanted to meet the expectations of their newly discovered stakeholders and pursue opportunities to take acceptable risk in order to win the regional competition.

\section{Implementing the Planning Process Group}

\subsection{Developing the Project Management Plan}

The project management plan, at either a summary or detailed level, defines how the project is to be executed, monitored and controlled, and closed [2]. A recent literature review indicates one of the challenges of successfully completing infrastructure projects is due to poor decision making during this planning phase [6]. With the contract serving as the project charter, the AISC Steel Manual and SSBC 2019 rules identified as the Enterprise Environmental Factors, and 20 plus year of historical information from previous Steel Bridge Teams serving as the Organization Process Assets, all of the inputs for the Project Management Plan were identified and available to the team [7]. The team did not create a formalized plan at a detailed level and instead moved forward believing their plan was captured adequately at a summarized level with the existing inputs. It was clear near the end of the first semester and into the second semester that this was a mistake. Taking the time to write out a detailed project management plan would have better identified individual roles and outlined necessary procedures for schedule, cost, change, and quality management. As often attributed to Benjamin Franklin, "If you fail to plan, you are planning to fail!" Unfortunately, for the Steel Bridge Team, issues with schedule, change, and quality management occurred throughout the project, leading to delays in how to handle them and issues with how they were handled. This was a lesson learned captured in the final project report (Organizational Process Asset) for future teams.

\subsection{Scope, Schedule, and Cost}

The PMBOK Guide defines scope as "the sum of the products, services, and results to be provided as a project" [2]. For the West Point Steel Bridge Team, the planning and closing processes were well-defined in their contract with the advisor with detailed deliverables and associated point values. However, the controlling and monitoring process consisting of approving and disapproving project changes was undefined and generally involved either a decision by the team captain or the team reaching out to one of the 
capstone advisors.

The Work Breakdown Structure, or WBS, is designed to give a hierarchical view of the activities that need to be completed by the project team. The team was encouraged to follow recommendations from others with project management experience, who have stressed the importance of forming structure in design work through detailed network planning and the construction of a clear and thorough precedence diagram of the scope in order to ensure the team is fully aware of the amount of work necessary for full project implementation [8]. While the team would create WBS to subdivide deliverables, they often waited do so until they were ready to start work on a major deliverable. While the PMBOK notes that this process can be performed at a predefined point in the project, the team found that performing this upfront at the start of the project would have been more beneficial to the project as a whole, especially as it pertained to scheduling. Often, detailed components of work were brought to the attention of the team through their advisor. In addition, a WBS would have been helpful have prior to the fabrication of the bridge, as it would have given the team a breakdown of how all of the bridge sections would fit together and shortened the fabrication time. The use of a top-down, bottom-up, or combined approach such as the "rolling wave" iterative style of planning would allow the team to more accurately approximate the time durations and resources required to complete the project [9].

Output from the periodic WBS was analyzed by the team using logic and experience from the team captain and developed into a Gantt chart. This Gantt chart was created at the start of each semester and served as a baseline to motivate the team to achieve goals on schedule. As issues arose due to changes or fabrication errors, the schedule would slip, and the systems engineer major, who controlled the Gantt chart, would edit the chart and create an updated schedule. During regularly scheduled weekly meetings with their capstone advisor, the team would compare updated schedules with the baseline and pursue opportunities to either compress the schedule by conducting activities in parallel or crashing the schedule by allocating more resources to certain activities to complete them earlier than planned.

While a more formal WBS would have led to a more accurate baseline schedule, the schedule planning that was conducted paid huge dividends for the team. Historically, the West Point team finishes their fabrication within a few days of the competition, leaving them with very little time to rehearse their construction of the bridge. The weekly schedule reviews of the Gantt chart (updated versus baseline) allowed the team to complete their fabrication two weeks prior to the competition. This allowed them to rehearse over 15 times which subsequently resulted in them cutting their construction time in more than half by the start of the competition.

With respect to estimating actual costs of creating a steel bridge, the West Point Steel Bridge Team's relationship with Brakewell Steel Fabricators, Inc, largely controls the cost of the bridge. With over 50 years of fabrication experience, the faculty advisor recognized both the competition benefits and educational opportunities that existed with the relationship. The team provided the fabricators with a set of drawings using modern engineering tools Autodesk (C Robot Structural Analysis Professional and Dassault Systèmes SOLIDWORKS $\subset$ and attended a meeting with the fabricator in their facility $[10,11]$. In this meeting, the students were able to tour the shop and utilize the fabricator's expertise to modify portions of their design. From a cost perspective, the fabricator worked within the given budget. In addition, AISC provided funds to help offset team costs. Thus, the traditional planning involved with funding a project did not really apply. However, the team was judged during the competition based on Structural Cost and Construction Cost, shown in Equation 1 and Equation 2, respectively.

Equation 1: Structural Cost Computation [1].

If measured weight does not exceed 120 pounds,

$$
\begin{gathered}
\mathrm{Cs}=(\text { Total weight }- \text { measured weight })(\text { pounds }) \times 5000\left(\frac{\$}{\text { pound }}\right) \\
+ \text { Aggregate deflection (inches) } \times 3,250,000\left(\frac{\$}{\text { inch }}\right)+\text { Load test penalties }(\$)
\end{gathered}
$$

If measured weight exceeds 120 pounds but does not exceed 200 pounds,

$$
\begin{aligned}
& \text { Cs }=(\text { Total weight }-120)(\text { pounds }) \times 5000\left(\frac{\$}{\text { pound }}\right) \\
& + \text { Aggregate deflection (inches }) \times 3,250,000\left(\frac{\$}{\text { inch }}\right)+\text { Load test penalties }(\$)
\end{aligned}
$$

If measured weight exceeds 200 pounds,

$$
\text { Cs }=(\text { Total weight }-184)(\text { pounds }) \times 25,000\left(\frac{\$}{\text { pound }}\right)
$$


+ Aggregate deflection (inches) $\times 3,250,000\left(\frac{\$}{\text { inch }}\right)+$ Load test penalties $(\$)$

Equation 2: Construction Cost Computation [1].

Cc $=$ Total time to construct (minutes) $\times$ number of builders (persons)

$\times 60,000\left(\frac{\$}{\text { person }}-\right.$ minute $)+$ Load test penalties $(\$)$

With the structural cost computations based primarily on weight and stiffness and assuming that few, if any bridges would be under 120 pounds, the team planned on generating alternatives and selecting a final design that was structurally stiff and under 200 pounds. To optimize construction costs, the team focused on ensuring each design had a minimal number of connections and ensured their schedule had adequate time to rehearse before the competition. As shown in Figure 4, the team decided weighing Structural Efficiency (8) over Construction Economy (2) would give them the best opportunity to win the regional competition. Using the metrics of weight, aggregate deflection, and number of connections to identify which design outperformed the other in each of these major categories, the final design for the 2018-2019 West Point Steel Bridge Team was Design 4.

\begin{tabular}{|c|c|c|c|}
\hline & $\begin{array}{c}\text { Construction } \\
\text { Economy }\end{array}$ & $\begin{array}{l}\text { Structural } \\
\text { Efficiency }\end{array}$ & \\
\hline Design Option & 2 & 8 & Total \\
\hline Option 1 & 1 & 1 & 10 \\
\hline Option 2 & 3 & 2 & 22 \\
\hline Option 3 & 2 & 3 & 28 \\
\hline \multirow[t]{2}{*}{ Option 4} & 4 & 4 & 40 \\
\hline & Best Option & \multicolumn{2}{|c|}{ Option 4} \\
\hline
\end{tabular}

Figure 4. The Four Preliminary Designs with Decision Matrix to Optimize Cost.

\section{Executing Process Group}

\subsection{Managing Quality}

By the start of the second semester, the design of the bridge was complete, and Brakewell Steel Fabricators, Inc. had completed fabricating the repetitive truss members. However, there were several other components of the bridge that required student fabrication. The PMBOK warns that prevention of a problem is preferred over inspection [2]. In other words, it would be better for the team to design quality into their bridge in lieu of finding a myriad of issues later on during inspection. Often times, project managers focus their project management on time and cost while minimizing quality. The consequence of this, as many project managers and Steel Bridge Teams have discovered in the past, is a completed project that fails to meet the expectations of the end users [12]. In order to improve the quality of the bridge, the West Point Steel Bridge Team elected to use Brakewell Steel Fabricators, Inc. to fabricate all of the repetitive members for the team was a big part of that process. With little to no welding and cutting experience on the team, the students turned to more experts, the laboratory technicians in the civil engineering program, for training and certification, as shown in Figure 5.

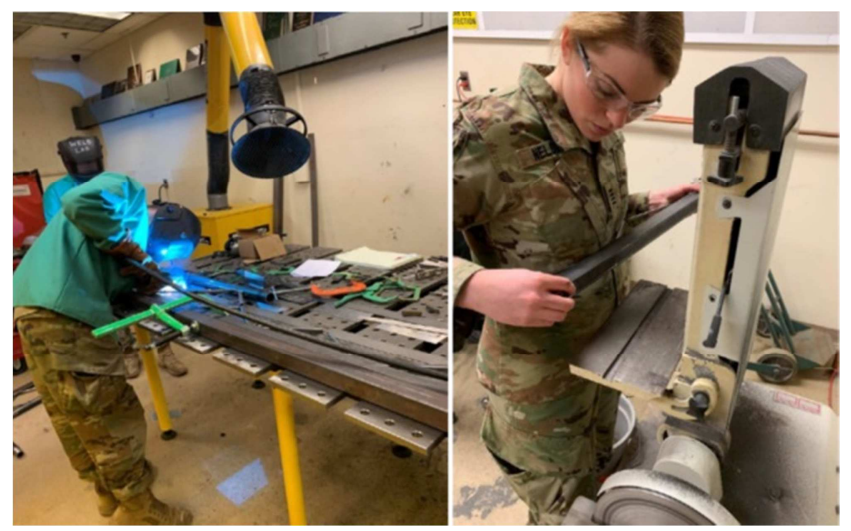

Figure 5. Fabrication and Safety Certification.

The team also managed quality by requiring at least one other student to check another student's work before it was considered correct. This "Design Review" process helped improve the quality of the product while getting them in the practice of what engineers in practice regularly do (check each other's work) and increasing their learning through repetition $[13,14,15]$. Students quickly saw the value of looking through each other's calculations. They were able to catch simple mathematical errors that would have had significant adverse effects on the project.

Once the team thought the fabrication of the bridge was complete, they managed the quality of the bridge through inspections. As shown in Figure 6, the team planned and executed a preliminary gravity and lateral load test of the bridge. The purpose of the inspections was to check the strength and stability of the bridge. Failure to meet the standards in either the gravity or lateral load tests results in an immediate disqualification from the competition. While conducting the inspections, the team gathered data to measure the bridge's performance and compare it against predicted software output. As a result of these inspections, the team discovered re-work was required for some of the welds done by the students and additional members were required to reduce the sway of the bridge. Building time into the schedule to conduct this inspection was a great idea; 
however, a lesson learned from this process was to allocate additional time in the schedule to both repair the defects and to re-inspect the bridge.

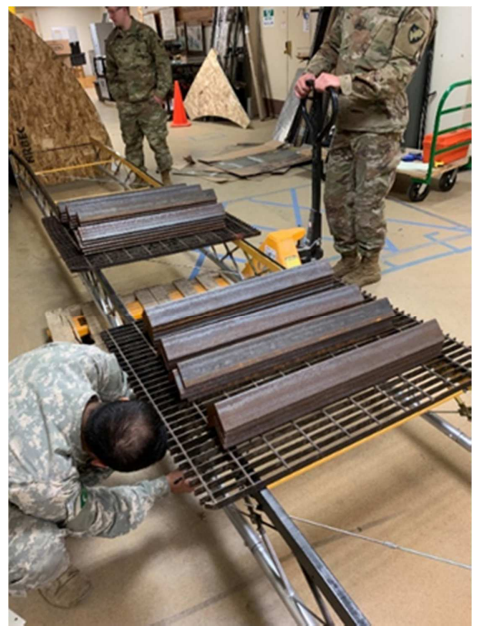

Figure 6. Managing Quality through Inspection.

\subsection{Developing and Managing the Team}

This was the first time the West Point Steel Bridge Team had incorporated a systems engineer on the team. Experts have studied the conflicts that arise out of forming interdisciplinary capstones and diverse teams and have published the causes of counterproductive conflict [16, 17]. Thus, development and management of the team was a focus of this year's West Point Steel Bridge Team. Special care and attention was taken by the advisors to focus on group decision making, work distribution, and conflict resolution strategies to keep the team moving in the right direction, approaches and recommendations published by experts in the capstone design mentoring field [18, 19]. All on the West Point Steel Bridge Team quickly found out that it was fortunate to have a systems engineer as a member of the team as this cadet prepared and executed a number of lessons on project management while using the PMBOK as a guide. While the civil engineer team members had completed a course in Construction Management, some of the terminology, process groups, knowledge areas, and tools and techniques were unfamiliar to some of them. As a result, the time taken to have the systems engineer cadet prepare and deliver the classes was value added to the project. Through the lens of an interdisciplinary capstone, it allowed the civil engineers on the team to understand the critical role of having a systems engineer on the team. Literature shows that diverse project teams tend to produce greater productivity, improved customer satisfaction, and fewer mistakes [20, 21]. Perhaps most importantly, the interdisciplinary approach allowed everyone on the team to acquire and apply new knowledge, using appropriate strategies from the PMBOK. With every cadet on the team on the verge of becoming platoon leaders (project managers) of their soldiers in the Army, lessons on the good practices in project management will undoubtedly serve them and their units well.
Initial project management lessons, as shown in Figure 7, focused on defining a project, the project life cycle, and the triple constraint. In each lesson that followed, special attention was given towards topics that were relevant to the Steel Bridge Capstone. For example, time and scope, from the triple constraint, were especially relevant in that they could break the success of the entire capstone project. Relevance and importance was demonstrated by connecting the Army Design Methodology to project management. Army leaders are called to be problem solvers, and they can use the Army Design Methodology to apply critical and creative systems thinking to solve both well-structured and extremely complex and ill-structured problems [22]. Subsequent lessons covered the role of the project manager and provided the team the opportunity to really see the value offered by having a systems engineer with a project management background on the team. Everyone was able to share their spheres of influence and competencies as the team was taking shape.

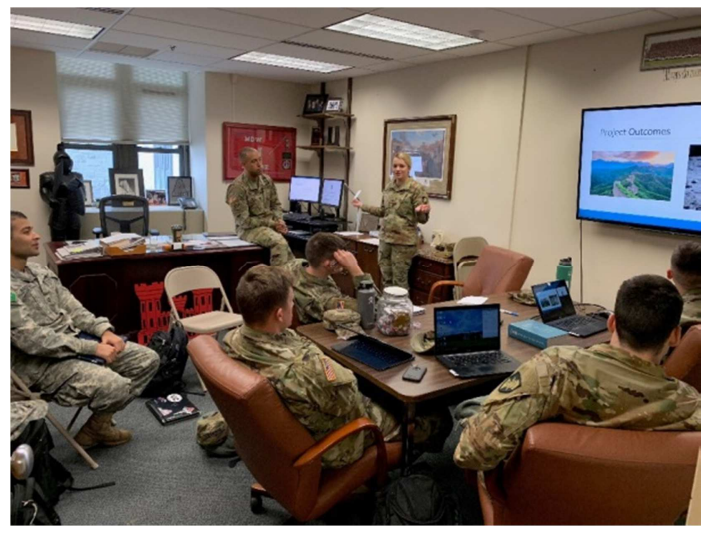

Figure 7. Project Management Lesson Defining a Project.

In the spirit of accounting for time spent on the project, the project manager collected each team member's billable hours. Students would regularly submit the amount of time spent on project management, administrative actions, design of the bridge, and fabrication of the bridge. As shown in Figure 8 , the project manager would then analyze the data and report the total billable hours (time spent outside of class) and the average amount of time spent per person per lesson. This, in conjunction with the schedule, allowed the project manager to both monitor effort and shift resources when required. Students found that the weekly review of the billable hours by the capstone advisor often motivated them to devote more and more time to the project.

- Billable Hours TOTAL: 212 hours

- Average Time PER PERSON: 1.5 hours

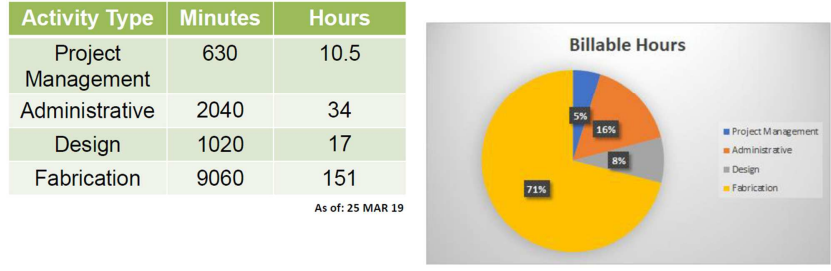

Figure 8. Snapshot of Billable Hours. 


\section{Monitoring and Controlling Process Group}

The PMBOK describes the Monitoring and Controlling Process Group as "those processes required to track, review, and regulate the progress and performance of the project" [2]. This was largely done by the capstone advisors through regular face-to-face meetings with the team. However, the primary capstone advisor was unavailable for face-to-face meetings during the spring semester. Thus, the team resorted to providing updates to the primary advisor over the phone and via e-mail. There were high standards for all reports and updates. The demand for professionalism and timely submissions were geared towards instilling discipline and teaching the students to take pride in their work. Updates included all progress made to meet performance objectives, with a focus on schedule, resources (nuts, bolts, paint, etc.), and quality.

\section{The Closing Process Group}

Unfortunately, the team did not pass the gravity load test in the regional competition. As shown in Figure 9, once the bridge carried 1,600 pounds, the judges noticed there was excessive lateral sway in the bridge (greater than one inch). The offset footer requirement led the bridge to experience more deflection on one side of the bridge than the other, precipitating the excessive sway.

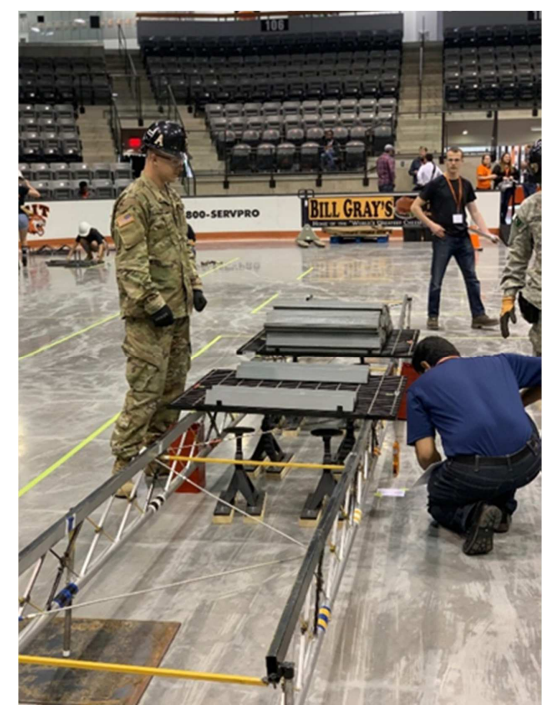

Figure 9. Gravity Load Test

While disappointed in the disqualification, the team did perform very well in other areas in large part due to effective project management. The team successfully constructed the bridge (shown in Figure 10) in 18 minutes and 23 seconds, which is the fastest time recorded from West Point in memory. The bridge passed the lateral load test and weighed in at 201.5 pounds, making it the second lightest bridge at the regional competition. Highlighting both the lessons learned and the successes at the West Point Project's Day was a significant part of the closing phase. For 30 minutes, the cadets were able to showcase their project management and engineering prowess to their stakeholders.

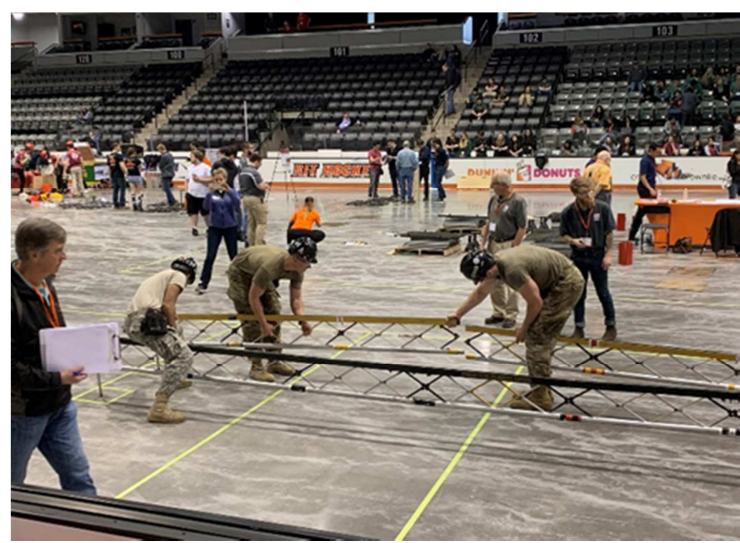

Figure 10. Bridge Assembly during Regional Competition.

Perhaps the most important part of the closing phase was an opportunity to communicate the lessons learned in a final report. The report, an organizational process asset, will be one of the first things read by future teams and is written to help them avoid mistakes and capitalize on successes. The \#1 take-away from the experience from the team: Project Management is critical to a successful project! As noted from one of the students, "This was my first experience as a project manager and I learned numerous lessons. I learned how essential project management really is to projects of all disciplines. If I could go back and do it again, I would have more strictly adhered to the PMBOK Process Groups. This would have given my job more legitimacy and would have kept the project more organized overall. I did not fully own my position as the group's project manager, and it was clear that I did not understand every aspect of my role. However, this experience has given me valuable lessons that I can take with me to future project management jobs, in or out of the Army."

\section{Conclusion}

Programs of higher education have the responsibility to prepare their graduates for an uncertain and complex tomorrow. As demonstrated in this paper, through the creation and mentoring of an interdisciplinary capstone team, two programs effectively provided an invaluable experience for their students. Students were given the opportunity to use previously learned knowledge and skills within their individual programs and disciplines and then applied this previously learned knowledge to a challenging problem with unlimited solutions. This experience promoted innovation and teamwork from a diverse group and resulted in the design, fabrication, and erection of a steel bridge during one academic year. More importantly, the experience served as a vital tool for the civil engineers as they learned Project Management Professional principles from the Project Management Institute from the system engineer. This also 
allowed the systems engineer to see another aspect of engineering design while learning the proper and safe use of tools in the construction of a steel bridge. Together, in conjunction with their project advisors (Figure 11), these students were able to unearth project management lessons learned that will serve all of them well as they prepare to serve as project managers for the organizations they will lead in the Army and in service to their nation.

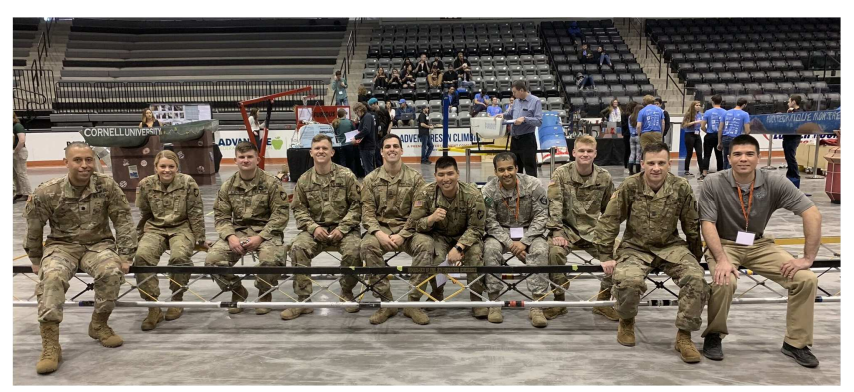

Figure 11. 2018-2019 West Point Steel Bridge Team.

\section{Acknowledgements}

We would like to thank AISC, Brakewell Steel, the United States Military Academy (especially the Department of Civil and Mechanical Engineering and the Department of Systems Engineering), and the Rochester Institute of Technology for their contributions allowing the West Point Steel Bridge Team to compete in the 2018-2019 competition.

\section{References}

[1] AISC Student Steel Bridge Competition Rules (2019). www.aisc.org/ssbc

[2] PMBOK Guide: A Guide to the Project Management Body of Knowledge (6th ed.). (2017). Newton Square, PN: Project Management Institute.

[3] Laufer, A. (1997). Simultaneous management. New York: AMACOM.

[4] Hayes, D. S. (2000). Evaluation and application of a project charter template to improve the project planning process: lessons for managing large development programs. Project Management Journal, 31 (1), 14-23.

[5] Eskerod, P., Huemann, M., \& Savage, G. (2015). Project Stakeholder Management-Past and Present. Project Management Journal, 46 (6), 6-14.

[6] Davies, A., MacAulay, S. C., \& Brady, T. (2019). Delivery Model Innovation: Insights From Infrastructure Projects. Project Management Journal, 50 (2), 119-127.

[7] Construction, AISC. (2017). Steel Construction Manual. American Institute of Steel Construction.

[8] Derenskaya, Yana. "Project Scope Management Process."
Baltic Journal of Economic Studies, vol. 4, no. 1, 2018, pp. 118-125., doi: 10.30525/2256-0742/2018-4-1-118-125.

[9] Githens, G. D. (2001). Manage innovation programs with a rolling wave. PM Network, 15 (5), 35-39.

[10] Autodesk@ Robot Structural Analysis Professional (2018).

[11] Dassault Systèmes SOLIDWORKSC (2018).

[12] Basu, Ron. "Managing Quality in Projects: An Empirical Study." International Journal of Project Management, vol. 32, no. $1, \quad 2014, \quad$ pp. 178-187., doi: 10.1016/j.ijproman.2013.02.003.

[13] Hill, A. (2018). Student Mastery of Structural Analysis with Design Review. Structures Congress 2018, https://doi.org/10.1061/9780784481349.052.

[14] Hamilton, Scott R. (2005). Peer Review: Modeling Civil Engineering Practice, Another Way To Improve Learning. Proceedings of the 2005 ASEE Annual Conference \& Exposition. Portland, OR: ASEE.

[15] Hamilton, S., \& Brunell, L., \& Tamm, G., \& Arnas, O. (2006). Peer Review In Engineering Courses As A Learning Tool. Paper presented at 2006 Annual Conference \& Exposition, Chicago, Illinois.

[16] Harper, Steven, and Robert Nagel. "A Study on Conflicts during an Interdisciplinary Capstone Design Experience." International Journal of Collaborative Engineering, vol. 1, no. 3-4, 2014, pp. 256-273., doi: 10.1504/IJCE.2014.063354.

[17] Randeree, Kasim. "The Management of Productivity and Resources: A Case Study in a Culturally Diverse Environment." International Journal of Technology, Knowledge and Society, vol. 3, no. 2, 2007, pp. 79-86., doi: 10.18848/1832-3669/CGP/v03i02/55725.

[18] Paretti, Marie \& Pembridge, J. J. \& Brozina, S. C. \& Lutz, Ben \& Phanthanousy, J. N. (2013). Mentoring team conflicts in capstone design: Problems and solutions. ASEE Annual Conference and Exposition, Conference Proceedings.

[19] Edwards, S. M. \& Edwards, S. M. (2002). The dream team, effectively leading and motivating diverse project teams. Paper presented at Project Management Institute Annual Seminars \& Symposium, San Antonio, TX. Newtown Square, PA: Project Management Institute.

[20] Moulton, David J., et al. Enhancing Productivity and Innovation in ECP with a Team of Teams Approach. Figshare, 2018.

[21] Edward J., Kinlaw, C. S., \& Kinlaw, D. C. (2000). Developing superior project teams: a study of the characteristics of high performance in project teams. Paper presented at PMI ${ }^{\circledR}$ Research Conference 2000: Project Management Research at the Turn of the Millennium, Paris, France. Newtown Square, PA: Project Management Institute.

[22] United States Army. (2015). Army Techniques Publication ATP 5-0.1 Army Design Methodology July 2015. Scotts Valley, CA: CreateSpace. 